\title{
Sensitivity of Numerical Weather Forecasts to Initial Soil Moisture Variations in CFSv2 0
}

\author{
PAul A. Dirmeyer AND SubHadeep Halder \\ Center for Ocean-Land-Atmosphere Studies, George Mason University, Fairfax, Virginia
}

(Manuscript received 11 March 2016, in final form 24 September 2016)

\begin{abstract}
When initial soil moisture is perturbed among ensemble members in the operational NWS global forecast model, surface latent and sensible fluxes are immediately affected much more strongly, systematically, and over a greater area than conventional land-atmosphere coupling metrics suggest. Flux perturbations are likewise transmitted to the atmospheric boundary layer more formidably than climatology-based metrics would indicate. Impacts are not limited to the traditional land-atmosphere coupling hot spots, but extend over nearly all ice-free land areas of the globe. Key to isolating this effect is that initial atmospheric states are identical among quantities correlated, pinpointing soil moisture and snow cover. A consequence of this high sensitivity is that significant positive impacts of realistic land surface initialization on the skill of deterministic near-surface temperature and humidity forecasts are also immediate and nearly universal during boreal spring and summer (the period investigated) and persist for at least 3 days over most land areas. Land surface initialization may be more broadly important for weather forecasts than previously realized, as the research focus historically has been on subseasonal-to-seasonal time scales. This study attempts to bridge the gap between climate studies with their associated coupling assessments and weather forecast time scales. Furthermore, errors in land surface initialization and shortcomings in the parameterization of atmospheric processes sensitive to surface fluxes may have greater consequences than previously recognized, the latter exemplified by the lack of impact on precipitation forecasts even though the simulation of boundary layer development is shown to be greatly improved with realistic soil moisture initialization.
\end{abstract}

\section{Introduction}

It is accepted that the state of the land surface can influence the atmosphere across a range of time scales, thanks to a number of weather and climate modeling studies. Most studies have focused on soil moisture, as it has the largest impact on subseasonal-to-seasonal time scales. Furthermore, the focus has been on time scales of weeks or months, out to seasonal scales, as it has been assumed that weather forecasts (on the order of hours to a few days) are an atmospheric initial value problem, and the state of the earth's surface is often neglected in deterministic forecasts (cf. WMO 2011). Thus,

Supplemental information related to this paper is available at the Journals Online website: http://dx.doi.org/10.1175/WAF-D-16-0049.s1.

Corresponding author address: Paul A. Dirmeyer, Center for Ocean-Land-Atmosphere Studies, George Mason University, Mail Stop 6C5, 4400 University Dr., Fairfax, VA 22030.

E-mail: pdirmeye@gmu.edu subseasonal-seasonal-interannual forecasts have been considered a boundary value problem within the domain of probabilistic forecasts (Waliser 2005). In fact, subseasonal time scales are a transition range where aspects of climate prediction are being brought to bear within the traditional weather forecast setting (Vitart and Robertson 2015).

A lingering problem has been that we have not observed the global state of soil moisture like we have been observing for decades ocean surface temperatures and atmospheric states. Recent satellite missions are beginning to address this problem with the coverage and accuracy needed to initialize global models (Kerr et al. 2001; Bartalis et al. 2007; Entekhabi et al. 2010), and data assimilation methodologies for soil moisture initialization are being implemented (e.g., van den Hurk et al. 2008; Reichle et al. 2008; Drusch et al. 2009; Dharssi et al. 2011; Santanello et al. 2016), but the difference between what a forecast model represents as soil moisture and what is measured in the field or by satellite greatly complicates initialization (Dirmeyer 2004; 
Koster et al. 2009). Historically, the best alternative has been to integrate the land surface component of global weather and climate models uncoupled from an atmospheric model but rather driven by observed gridded analyses of surface meteorology, including precipitation and radiation (e.g., Rodell et al. 2004; Dirmeyer et al. 2006). The land surface states from such simulations have been used to initialize operational weather and climate models (Saha et al. 2010; Kobayashi et al. 2015; Boisserie et al. 2016), but the expectations from modeling centers for improved forecasts from better land surface initialization seems to remain at medium-range weather and longer time scales (e.g., Merryfield et al. 2013; Vitart et al. 2016).

Model sensitivity studies established that the state of the atmosphere is responsive to soil moisture variations (e.g., Shukla and Mintz 1982; Meehl and Washington 1988; Delworth and Manabe 1989; Cook and Gnanadesikan 1991; Dirmeyer 1999; Koster et al. 2000; Douville 2003). Although there is considerable variability among the behavior of different models, a consensus has emerged that certain regions of the globe in each season act as "hot spots" of land-atmosphere coupling through the water and energy cycles (Koster et al. 2004). Hot spots are locations where variations in land surface properties, namely soil moisture, are shown to generate a significant response in atmospheric conditions such as near-surface air temperature or precipitation. These hot spot regions are most prevalent in the midlatitudes during the local warm season and in the subtropics, generally located in transition regions between arid and humid climates (e.g., Dirmeyer 2011; Wei and Dirmeyer 2012). The original coupling metric was based on the reduction of ensemble spread that resulted from specifying identical soil moisture conditions in every member of an ensemble of seasonal retrospective forecasts (Koster et al. 2002). Sensitivity of the atmosphere to soil moisture is largely dictated by whether surface evapotranspiration is more limited by a lack of available energy or a lack of moisture in the soil (Dirmeyer et al. 2009). Further studies established that realistic initialization of subseasonal-to-seasonal forecasts improved forecast skill (Koster et al. 2010, 2011). The need for improved monitoring and real-time analysis of global soil moisture was established by such research.

A range of metrics has been developed to assess in models and nature the degree and character of landatmosphere feedbacks (e.g., Schlosser and Milly 2002; Findell and Eltahir 2003; Notaro 2008; Zeng et al. 2010; Dirmeyer 2011; Taylor et al. 2011; Roundy et al. 2014). Such metrics typically focus on one of two segments of the feedback pathway: the terrestrial segment that links land states to surface fluxes that affect the atmosphere near the surface and the atmospheric segment that quantifies the responsiveness of the troposphere to surface fluxes (Guo et al. 2006). In both segments, the feedbacks operate through the water and energy cycles. Most metrics are defined around a covariance or contingency relationship between variables expected to be physically connected through feedback processes, which are typically calculated on a monthly or seasonal basis. Recently, more attention is being paid to the diurnal cycle and its associated metrics (e.g., Ek and Holtslag 2004; Santanello et al. 2009; Findell et al. 2011; Gentine et al. 2013; Tawfik and Dirmeyer 2014).

From these assessments, an assumption has been broadly asserted that accurate initialization of soil moisture should have the greatest positive impact on forecasts in those locations where coupling metrics indicate hot spots exist. However, such metrics have routinely been developed using a large amount of data spanning all days in a month or season across many years. In other words, they represent a climatological status of land-atmosphere coupling. Guo and Dirmeyer (2013) showed that there is considerable interannual variability in the location and strength of hot spots.

We contend that an assessment of the processes by which land surface initialization affects the first days of a forecast has been lacking. Historically, initial land surface states have been taken from an uncoupled land model analysis driven by observationally based meteorological forcings (e.g., Rodell et al. 2004) or unadvisedly from a completely different source than the forecast model (cf. Koster et al. 2009). There have been some efforts made to improve land surface initialization for weather forecast applications using data assimilation (see the review by de Rosnay et al. 2014), as sensitivity to the land surface state may affect the deterministic evolution of the atmosphere, not just its statistical nature over the course of weeks. Tawfik and Dirmeyer (2014) showed that there is an immediate impact of land surface states on boundary layer development that, together with the properties of the atmospheric profile of temperature and humidity, can have profound effects on the triggering of cloud formation and precipitation, becoming the basis of a new convective triggering parameterization (Bombardi et al. 2016). For an answer to the question of initializing forecasts, we need to know whether surface fluxes or atmospheric states are sensitive to a perturbation (or error) in initial soil moisture and, furthermore, whether that sensitivity exhibits a systematic behavior that can impact forecast skill.

In this study, we use the operational global forecast model of the National Weather Service to determine this sensitivity beginning on day 1 of the forecast. Section 2 describes the global model and experiment design. Coupling metrics, typically applied on monthly to seasonal scales, are assessed in the first days of the forecasts in 
section 3. The impact on forecasts on weather time scales is shown in section 4. Section 5 presents discussion and our conclusions.

\section{Model simulations}

The global general circulation model used in this study is version 2 of the Coupled Forecast System (CFSv2; Saha et al. 2014) of the National Centers for Environmental Prediction. CFSv2 consists of the Global Forecast System, version 2 (GFSv2) atmospheric model coupled to the Modular Ocean Model, version 4 (MOM4; Griffies et al. 2004). Although the coupled ocean component is of little consequence for this study of the first days of forecasts, the simulations examined are actually many months long. The atmospheric horizontal resolution is approximately $0.9^{\circ}$ (T126 spectral resolution), and the ocean has a horizontal resolution of $0.5^{\circ}$, increasing to $0.25^{\circ}$ in the meridional dimension near the equator. Han and Pan (2011) describe updates to the atmospheric physics in GFSv2, which include a revised implementation of the Hong and Pan (1996) boundary layer scheme that has enhanced turbulent diffusion in areas of stratocumulus to reduce low cloud, and updated shallow and deep convection. The atmosphere has 64 vertical levels with 16 levels below $800 \mathrm{hPa}$, and the ocean has 40 levels. Sea ice is predicted using a modified version of the Geophysical Fluid Dynamics Laboratory (GFDL) Sea Ice Simulator (cf. Saha et al. 2010). The land surface model is the Noah LSM (Ek et al. 2003), version 2.7.1, a "second generation" land surface scheme that models the surface energy and water budgets and estimates the transpiration component of evapotranspiration based on plant water stresses. Noah has four soil layers extending to a depth of $2 \mathrm{~m}(0.1$, $0.3,0.6$, and $1.0 \mathrm{~m}$ thick).

The source of both the model initialization and forecast validation is the NCEP CFS Reanalysis (CFSR; Saha et al. 2010). CFSR has a higher horizontal resolution $\left(\mathrm{T} 382, \sim 0.3^{\circ}\right)$ than the forecast configuration used in this study, but still employs 64 vertical levels. The sea surface temperature (SST) analysis for the ocean in CFSR uses two daily SST analyses at $0.25^{\circ}$ developed using an optimum interpolation scheme. The first is an AVHRR-only SST dataset (November 1981-May 2002) and the second is a combined AMSR-E and AVHRR SST data from June 2002 onward (Reynolds et al. 2007). Assimilated sea ice concentrations are derived from several datasets (Grumbine 1996; Cavalieri et al. 1996, 2007; Saha et al. 2010). Land states in CFSR are reset every $24 \mathrm{~h}$ at 0000 UTC from offline simulations of Noah using atmospheric forcing from the GFS Data Assimilation System (GDAS) and precipitation based on a blend of observed global analyses (Xie and Arkin 1997;
Xie et al. 2007) and the 6-hourly precipitation generated by GFSv2. In this methodology, the land surface model is said to be "semicoupled" to the atmosphere. Further details about the preparation of CFSR can be found in Saha et al. (2010).

For this study, ensemble retrospective forecast simulations are initialized in each of $28 \mathrm{yr}$ spanning 1982 2009, at 0000 UTC on the first day of April, May, and June, a period of transition to strongly coupled landatmosphere conditions across much of the Northern Hemisphere (Dirmeyer 2011; Guo et al. 2012). For each initial date, the baseline ensemble member (Control run) is initialized from CFSR for that date. The other ensemble members are initialized with the same atmosphere, sea ice, and ocean states as in the baseline simulation, but with initial land states taken from the corresponding month and day of each of the remaining $27 \mathrm{yr}$ to achieve the maximum initial land perturbation. As such, one member can be considered to have the "right" global land initial state, and the other $27 \mathrm{mem}$ bers effectively have a "wrong" global land state that is highly perturbed. Figure S1 in the online supplement to this article (http://dx.doi.org/10.1175/WAF-D-16-0049.s1) shows the range of initial soil moisture values across the 28-yr span for each of the three initialization dates for the top two soil layers. For purposes of understanding the impacts of land surface initialization, we consider that each ensemble of 28 forecasts has 378 possible differences calculable from pairs of initial land states (28-choose-2 combinations) and likewise in the 1-day differences in surface fluxes and atmospheric variables. Land surface states, particularly soil moisture, can affect the atmosphere by their control on surface fluxes in the energy and water budgets. We calculate correlations and the slope of the linear regressions (sensitivity) for each ensemble between soil moisture (surface layer, which directly affects surface temperature and evaporation, and the second layer, which impacts transpiration) and surface fluxes (latent and sensible heat fluxes), and between the surface fluxes and boundary layer states (height of boundary layer and boundary layer cloud fraction). We then average across all 28 ensembles to ascertain the impacts of land initialization on the terrestrial and atmospheric segments of coupling, respectively. This approach follows the process chain of land-atmosphere coupling (Santanello et al. 2011). Note that this is not the same as previous climatological metrics because in each case the initial atmospheric state is identical for all terms that go into a correlation or sensitivity calculation. As such, the regime of the atmosphere has no bearing on the calculated coupling indices.

Finally, forecast validation is relative to CFSR, but the 28 simulations with the right global initial land states are 

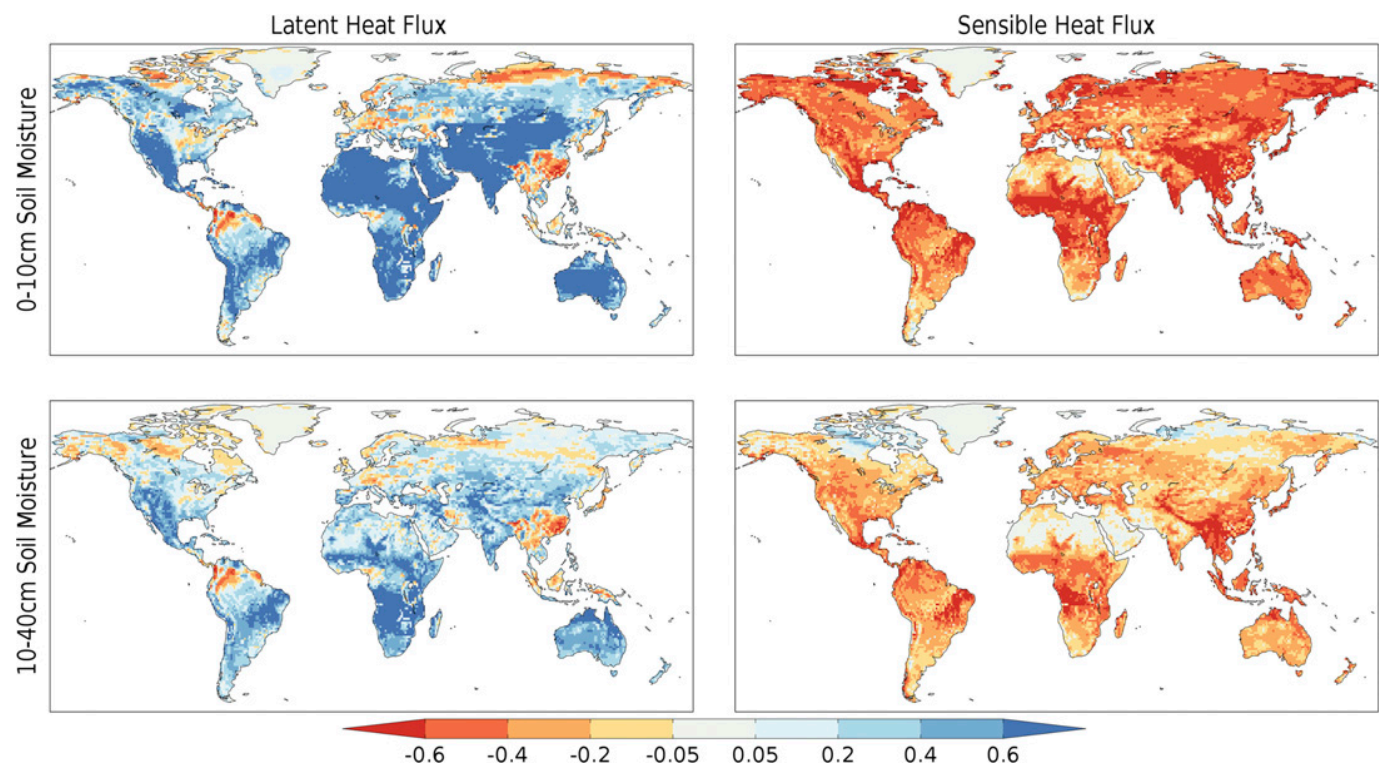

FIG. 1. Correlations between daily soil moisture (layers indicated on the left) and surface heat fluxes (indicated at the top) across days 3-7 of all forecast ensemble members for years 1982-2009 (784 simulations) initialized on 1 Jun. Magnitudes greater than 0.05 are significant at the $95 \%$ confidence level.

considered as one set for the purposes of estimating the interannual anomaly correlation coefficients (ACC; the forecast skill metric), and 27 other ensembles of 28 simulations (always one atmosphere/ocean initialization from each of the years during 1982-2009 and jumbled, nonrepeating perturbed initial land states) are used for comparison, with the average of the ACCs from the 27 ensembles being the metric for the wrong initial land states.

\section{Land-atmosphere coupling}

In this section we describe only results for the 1 June initialized retrospective forecasts, but corresponding figures for 1 April and 1 May cases are provided in the supplemental material online, so some notion of the evolution from boreal spring into summer can be discerned, including snow impacts (cf. Dirmeyer 2013). The correlations between soil moisture and surface heat fluxes calculated as a standard terrestrial coupling metric, using forecasts from days 3 to 7 from all 784 forecasts spanning the $28 \mathrm{yr}$, are shown in Fig. 1 (Figs. S2 and S3 for April and May). This estimate samples across intraseasonal and interannual variability in atmospheric states at each location, as well as various soil moisture conditions, providing a climatological picture of landatmosphere coupling in CFS during early June, analogous to previous studies. For such a large sample, the threshold for significance is low and only the pale-grayshaded areas fail to achieve statistical significance at the
$95 \%$ confidence level. The strongest correlations between soil moisture and latent heat fluxes are over arid, semiarid, and subtropical regions. Anticorrelations with sensible heat fluxes are strong over most locations except very arid regions and ice sheets. Correlations in general are stronger with surface layer soil moisture than subsurface moisture. These results are consistent with those found with other models (e.g., Guo et al. 2006; Dirmeyer et al. 2013a,b; Cheruy et al. 2014; Berg et al. 2015).

Correlations between differences in initial soil moisture states and differences in day 1 surface fluxes among pairs of forecasts where the initial atmospheric and oceanic states are identical (i.e., from within the same ensemble) show an extremely strong response (Fig. 2; Figs. S4 and S5 for April and May). Over nearly every ice- and snow-free location, the correlations are greater than \pm 0.6 . For correlations between 0 - and 10 -cm soil moisture and latent heat flux, the median is greater than 0.68 and for the sensible heat flux the median is -0.73 . Correlations are lower for $10-40-\mathrm{cm}$ soil moisture but are still much stronger than for the standard coupling metric in Fig. 1. This indicates that nearly everywhere, over a much larger area than the traditional terrestrial coupling hot spots, a perturbation (or error) in initial soil moisture leads to a systematic response in surface heat fluxes.

Furthermore, the spatial patterns between the latent and sensible heat flux correlations are much greater in Fig. 2: -0.52 between the top two panels versus -0.08 for the corresponding panels in Fig. 1. This makes sense 

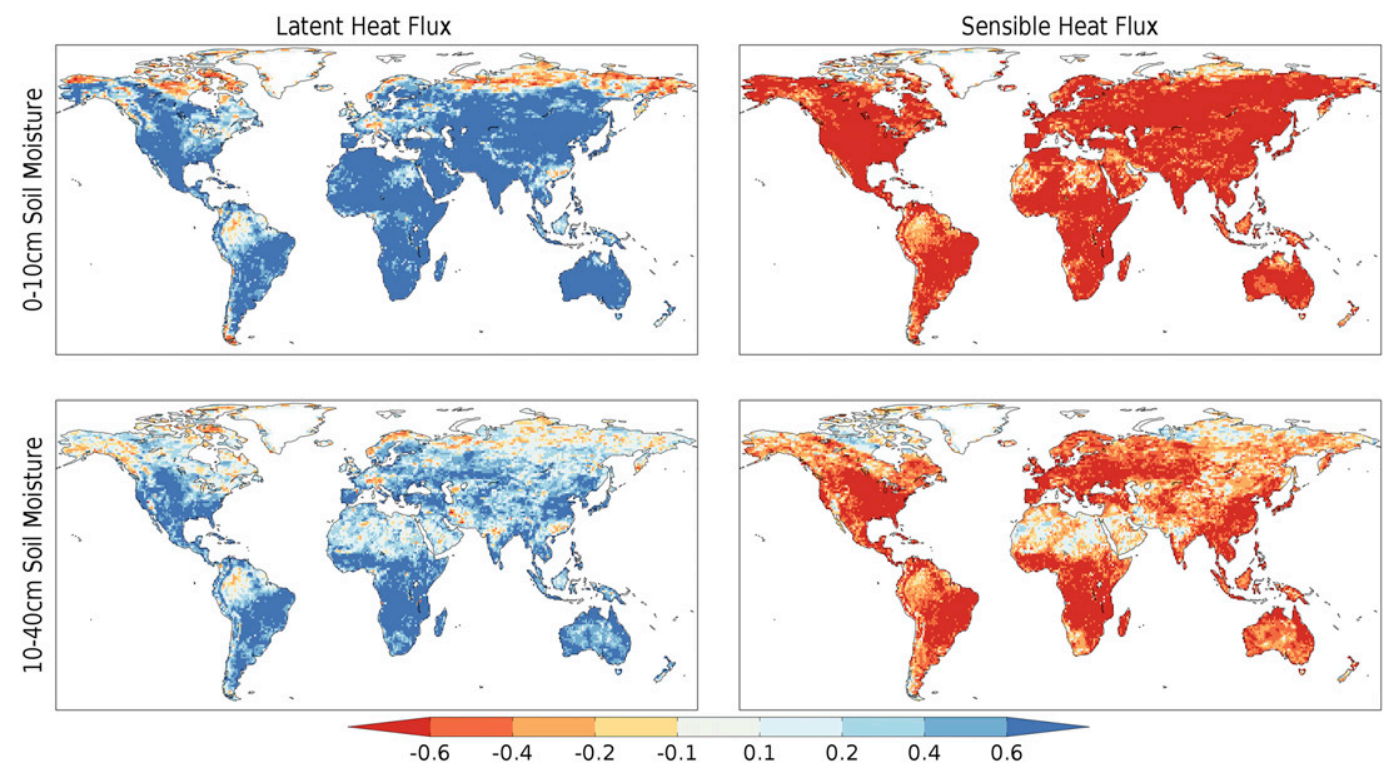

FIG. 2. Correlations between differences in 1 Jun initial soil moisture between ensemble members with identical 1 Jun initial atmospheric and oceanic states (layers indicated on the left) and corresponding differences in day 1 surface heat fluxes (indicated at the top). Magnitudes greater than 0.10 are significant at the $95 \%$ confidence level.

in that identical atmospheric states lead to nearly identical downward total radiation on day 1 and, thus, very similar net radiation. This means the main effect of soil moisture differences within this context is to alter the partitioning of net radiation between sensible and latent heat fluxes, fostering a strong anticorrelation between the two quantities.

The nearly universal correspondence of surface flux perturbations to initial soil moisture perturbations would be inconsequential for weather and climate forecasting if the atmosphere were not responsive. Figure 3 shows correlations for aspects of the atmospheric segment of the coupling, namely between the sensible heat flux and boundary layer properties (Figs. S6 and S7 for April and May). There is an extremely robust response of boundary layer depth to perturbations in the sensible heat flux, consistent with theory (Betts 2004). There is also a strong inverse relationship over humid and semihumid regions between sensible heat flux perturbations and boundary layer cloud, consistent with the findings of Findell et al. (2011), as reduced sensible heat flux corresponds to greater latent heat flux and more favorable conditions for convective rainfall in such areas. The top and bottom panels in Fig. 3 show the responsiveness of the atmosphere in the energy and water cycles, respectively.

Correlations indicate covariance, but the implications of soil moisture perturbations on the atmosphere are important only if the magnitude of the response is sufficiently large. Sensitivity to initial soil moisture perturbations is quantified by the slope of the best-fit linear regression of surface fluxes on surface soil moisture and of boundary layer height on sensible heat flux, which are shown in Fig. 4 (Figs. S8 and S9 for April and May). Locations where correlations in Figs. 2 and 3 explain less than
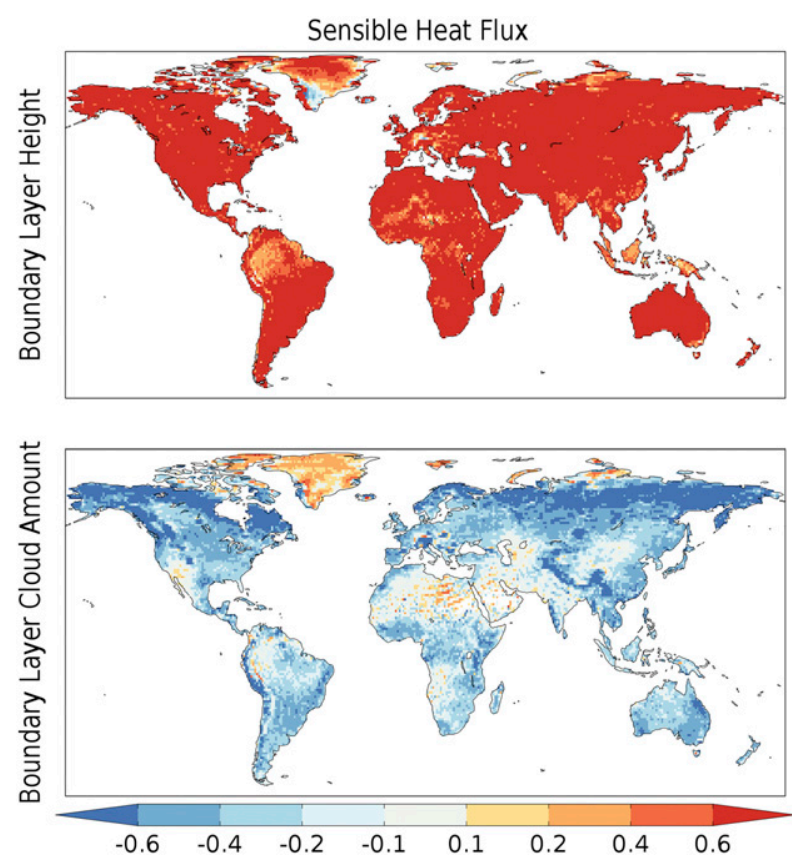

FIG. 3. As in Fig. 2, but for correlations between differences in day 1 sensible heat flux and day 1 boundary layer properties (indicated on the left). Magnitudes greater than 0.10 are significant at the $95 \%$ confidence level. 

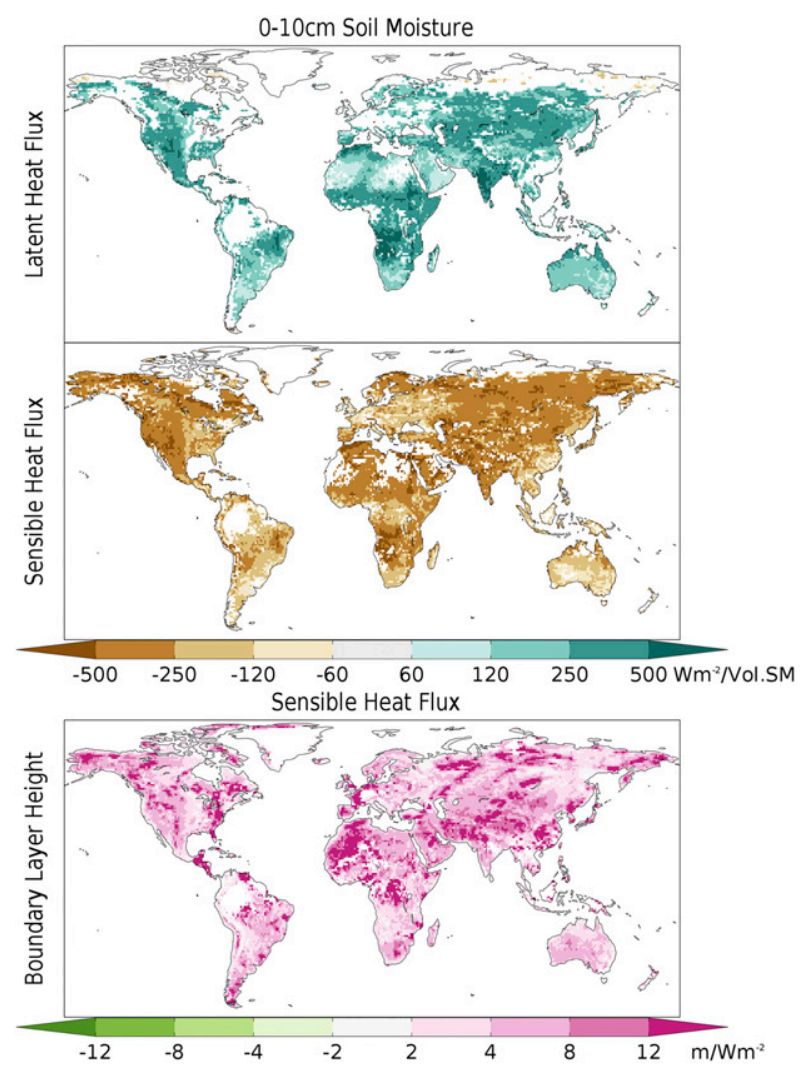

FIG. 4. Slope of the best-fit linear regression of differences in day 1 flux or boundary layer height (indicated on the left) on the presumed forcing (indicated at top). Regions where the magnitude of correlations between the two terms is less than 0.5 are masked out.

$25 \%$ of the variance (magnitudes less than 0.5 ) are masked out. Note the units of the slopes; for the top two panels, the denominator is volumetric soil moisture (Vol.SM), which typically has a range between 0 and $\approx 0.45$ (refer to Fig. S1 for the distribution of the active ranges). So, for example, a value of $250 \mathrm{~W} \mathrm{~m}^{-2} / \mathrm{Vol}$. SM means a 0.1 change in volumetric soil moisture would result on average in a change in the flux of $25 \mathrm{~W} \mathrm{~m}^{-2}$. The magnitude and spatial extent of the sensitivities are considerable in all panels and are always of uniform sign across the globe for each relationship.

Results for April (Figs. S2, S4, S6, and S8) are similar except over high northern latitudes, where signals are much weaker for relationships between the soil moisture and surface fluxes over snow cover. Snow cover isolates the atmosphere from the soil, preventing soil moisture from having a direct connection to the surface fluxes. Also, in those regions there is little or no interannual variation in snow cover fraction (essentially $100 \%$ covered), and the differences in snow depth have little consequence after only 1 day. However, relationships between the sensible heat flux and boundary layer properties remain strong even over snow, driven by fluctuations in snow-air temperature gradients and net radiation. May results (Figs. S3, S5, S7, and S9) indicate the transition between April and June, with the recession of snow cover toward the north seen very clearly.

\section{Forecast skill}

The coupled response of the atmosphere to variations in the initial state of the land surface have a degree of persistence that affects forecasts on weather, subseasonal, and even seasonal time scales. Here, we focus on deterministic (weather) forecasts of daily averages validated against CFSR. Figure 5 shows the duration of skill improvement for forecasts of temperature and humidity initialized on the first day of April, May, and June on weather time scales. Colored shading indicates the number of days that the skill of forecasts with realistic land surface initialization, measured as the interannual ACC, remains at least one standard deviation above the mean from all the forecasts with jumbled land surface initialization. The standard deviation is calculated among just the simulations with the jumbled land initial conditions, but because of the extreme nature of those variations, one standard deviation is actually a rather large hurdle to surmount compared to climatological land initialization, or small perturbations in initial states typical of operational weather forecasting. Thus, we use it as a threshold for significance.

Deterministic air temperature forecasts are significantly improved for three or more days over $52 \%-59 \%$ of the shaded land surface in the figures. Considerable areas show improvements lasting seven or more days (shades of green and blue). The weakest improvements, typically 1-2 days, are found over very arid or very humid regions, where the natural range of soil moisture does not induce much variation in the surface fluxes (see Fig. S1), and over completely snow-covered areas (mainly in April) that experience little variation in snow cover fraction during the first third of the month. Humidity forecast improvements lasting at least 3 days cover $52 \%-$ $53 \%$ of the land area. The lack of improvement over snowcovered, arid, and humid (namely the Amazon basin) regions is stark, but elsewhere the improvements tend to persist nearly as long as for temperature.

Figure 6 applies this assessment to the predicted height of the planetary boundary layer and the precipitation. Boundary layer forecast improvements persist nearly as long as temperature and humidity and are as widespread as for those quantities. This is an indication that surface fluxes are responding to the soil moisture initialization in a way that is conducive to improving the profile of the lower troposphere, not just the 2-m meteorological 

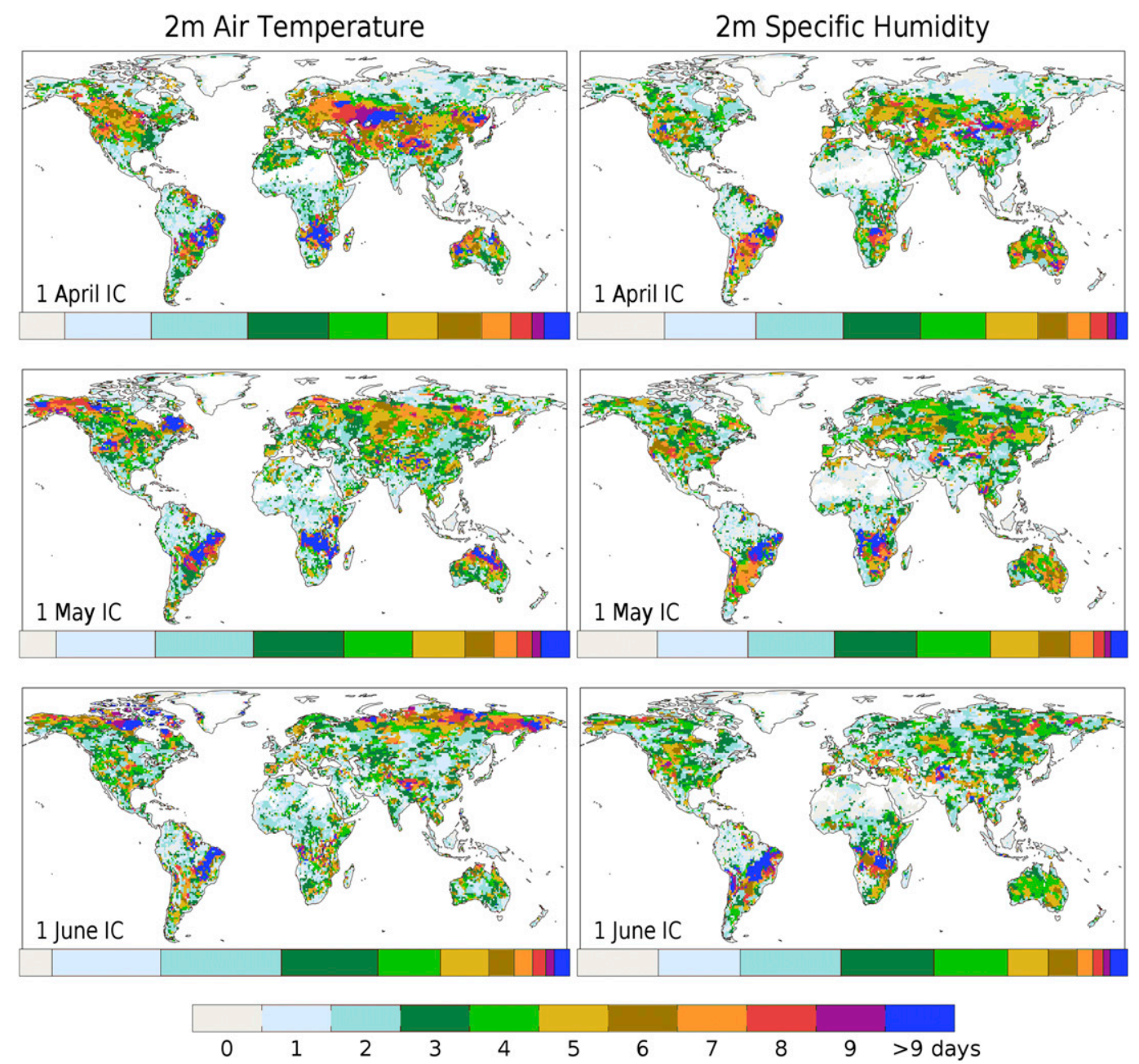

FIG. 5. Numbers of days into the forecast when the interannual ACCs of (left) 2-m air temperature and (right) humidity with realistically initialized land surface states remain at least one standard deviation above the mean from all forecasts with random land initialization. The color bars beneath each panel show the fraction of land area in each category.

quantities. Interestingly, these improvements do not translate at all in GFSv2 to broadly improved precipitation forecasts. Convective precipitation is tightly coupled to boundary layer development, but this model has demonstrated problems with the statistics of precipitation (Dirmeyer 2013; Shin and Huang 2016; Lien et al. 2016) and its connection to surface fluxes (Zhang et al. 2011). Thus, this result should not be taken to indicate that land surface initialization can do nothing to improve precipitation forecasts. Rather, it points out that model shortcomings can hamper the ability to realize potential predictability from the land surface.

\section{Summary and conclusions}

Many studies have established a climatological relationship between soil moisture, surface fluxes, and the lower troposphere that varies spatially, seasonally, and even interannually. These findings have been based on quantitative metrics that relate soil moisture to fluxes and atmospheric states compiled typically over many days, months, or years across a range of atmospheric and land surface conditions at every location. In this study, we remove the variability of atmospheric states and examine the relationship between differences in soil moisture and snow to corresponding differences in surface fluxes, near-surface meteorology, and boundary layer properties among pairs of ensemble members from 28 ensembles of global model forecasts covering boreal spring and summer with identical initial states except at the land surface. This provides a clean isolation of the land surface impact on the atmosphere, concentrating on the differences in the first hours and days of the forecasts. The results have consequences for initialization 

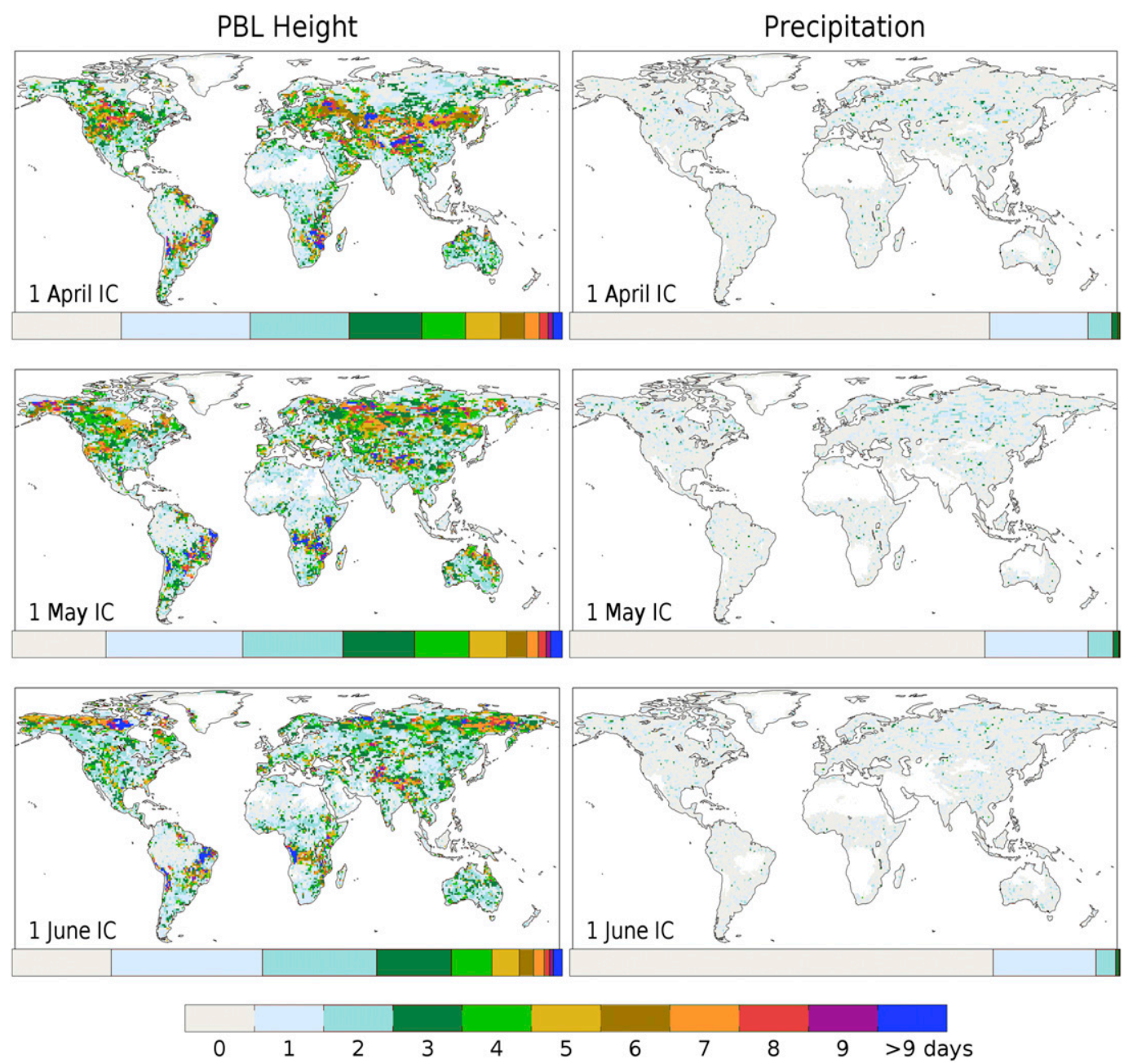

FIG. 6. As in Fig. 5, but for the (left) height of the planetary boundary layer and (right) precipitation.

of the land surface for weather forecasts as well as climate forecasts, helping bridge the gap between what have traditionally been considered the atmospheric initial value problem of weather and the atmospheric boundary value problem of climate.

We find extremely widespread strong correlations between differences in initial soil moisture states and the day 1 differences in surface heat fluxes when the initial atmospheric states are identical in CFSv2, the global model used for operational climate forecasting at NCEP whose atmospheric and land components are those used for operational weather forecasts. This strong correspondence is carried upward into the atmosphere, in the form of correlations between day 1 differences in boundary layer properties and the surface flux differences. These strong correlations are accompanied by substantial sensitivities over most locations, quantified as the change in response per unit change in forcing (the slope of the linear regression of the response on the forcing). Taken together, these results suggest that variations in land surface initialization may be extremely important not only for subseasonal-to seasonal-forecasts, where soil moisture initialization is assumed to have the greatest impact, but also on weather times scales beginning on day 1 of the forecast. Excluding precipitation, in this model skill improvements in deterministic (daily mean) forecasts are shown to extend out for about 3 days over half of the land areas and at least a week for up to $15 \%$ of the land areas.

From these results, the need is even clearer for operational global land data assimilation systems that produce accurate global soil moisture analyses for routine use in weather and climate forecasts. This should include higher-resolution land surface analyses that capture heterogeneity on native scales of land-atmosphere interactions, which remain below the resolution of many regional and all global models. The highly coupled and sensitive nature of the responses demonstrated in this 
experiment further advocate for data assimilation to take place within a coupled land-atmosphere framework, to ensure that the initial states in both components are consistent and in balance with one another.

A noteworthy result is that improvements are not found for precipitation forecasts. Combined with previous research, this result suggests that any biases or otherwise incorrect responsiveness of atmospheric parameterizations (such as for shallow or deep convection, clouds, the planetary boundary layer, or other aspects of turbulent mixing or diffusion) to surface heat flux perturbations could result in an incorrect response of the atmosphere to a "correct" land surface anomaly, failing to improve the forecast or even degrading it. As the body of quality-controlled observational data for land surface states (e.g., Dorigo et al. 2011; Quiring et al. 2015) and surface fluxes (e.g., Baldocchi et al. 2001; Abramowitz 2012) grows, our capability to perform coupled land-atmosphere model development and validation to address coupled biases will also progress.

Acknowledgments. We thank the National Monsoon Mission, Ministry of Earth Sciences, government of India for support for this study. This work used computational resources from the Extreme Science and Engineering Discovery Environment (XSEDE) program, as supported by National Science Foundation Grant ACI1053575. Specifically, we acknowledge the Texas Advanced Computing Center (TACC) at The University of Texas at Austin for providing high-performance computing resources. Data from all simulations are archived on the TACC Ranch advanced storage resource. The assistance of Lawrence Marx was crucial to the successful execution of the modeling experiments.

\section{REFERENCES}

Abramowitz, G., 2012: Towards a public, standardized, diagnostic benchmarking system for land surface models. Geosci. Model Dev., 5, 819-827, doi:10.5194/gmd-5-819-2012.

Baldocchi, D., and Coauthors, 2001: FLUXNET: A new tool to study the temporal and spatial variability of ecosystem-scale carbon dioxide, water vapor, and energy flux densities. Bull. Amer. Meteor. Soc., 82, 2415-2434, doi:10.1175/1520-0477(2001)082<2415: FANTTS $>2.3 . \mathrm{CO} ; 2$.

Bartalis, Z., W. Wagner, V. Naeimi, S. Hasenauer, K. Scipal, H. Bonekamp, J. Figa, and C. Anderson, 2007: Initial soil moisture retrievals from the METOP-A Advanced Scatterometer (ASCAT). Geophys. Res. Lett., 34, L20401, doi:10.1029/2007GL031088.

Berg, A., and Coauthors, 2015: Interannual coupling between summertime surface temperature and precipitation over land: Processes and implications for climate change. J. Climate, 28, 1308-1328, doi:10.1175/JCLI-D-14-00324.1.

Betts, A. K., 2004: Understanding hydrometeorology using global models. Bull. Amer. Meteor. Soc., 85, 1673-1688, doi:10.1175/ BAMS-85-11-1673.
Boisserie, M., B. Decharme, L. Descamps, and P. Arbogast, 2016: Land surface initialization strategy for a global reforecast dataset. Quart. J. Roy. Meteor. Soc., 142, 880-888, doi:10.1002/ qj.2688.

Bombardi, R. J., and Coauthors, 2016: The heated condensation framework as a convective trigger in the NCEP Climate Forecast System version 2. J. Adv. Model. Earth Syst., 8, 13101329, doi:10.1002/2016MS000668.

Cavalieri, D. J., C. Parkinson, P. Gloersen, and H. J. Zwally, 1996: Sea ice concentrations from Nimbus-7 SMMR and DMSP SSM/I-SSMIS passive microwave data, version 1. Subset used: Northern Hemisphere daily data (updated yearly), NASA National Snow and Ice Data Center Distributed Active Archive Center, doi:10.5067/8GQ8LZQVL0VL.

,,$-- \ldots$, and,- 2007 : Sea ice concentrations from Nimbus-7 SMMR and DMSP SSM/I passive microwave data, 1978-1996. National Snow and Ice Data Center.

Cheruy, F., J. L. Dufresne, F. Hourdin, and A. Ducharne, 2014: Role of clouds and land-atmosphere coupling in midlatitude continental summer warm biases and climate change amplification in CMIP5 simulations. Geophys. Res. Lett., 41, 64936500, doi:10.1002/2014GL061145.

Cook, K. H., and A. Gnanadesikan, 1991: Effects of saturated and dry land surfaces on the tropical circulation and precipitation in a general circulation model. J. Climate, 4, 873-889, doi:10.1175/ 1520-0442(1991)004<0873:EOSADL >2.0.CO;2.

Delworth, T. L., and S. Manabe, 1989: The influence of soil wetness on near-surface atmospheric variability. J. Climate, 2, 1447-1462, doi:10.1175/1520-0442(1989)002<1447:TIOSWO>2.0.CO;2.

de Rosnay, P., G. Balsamo, C. Albergel, J. Muñoz-Sabater, and L. Isaksen, 2014: Initialisation of land surface variables for numerical weather prediction. Surv. Geophys., 35, 607-621, doi:10.1007/s10712-012-9207-x.

Dharssi, I., K. Bovis, B. Macpherson, and C. Jones, 2011: Operational assimilation of ASCAT surface soil wetness at the Met Office. Hydrol. Earth Syst. Sci., 15, 2729-2746, doi:10.5194/ hess-15-2729-2011.

Dirmeyer, P. A., 1999: Assessing GCM sensitivity to soil wetness using GSWP data. J. Meteor. Soc. Japan, 77, 367-385.

_, 2004: Soil moisture-Muddy prospects for a clear definition. GEWEX News, Vol. 1, No. 3, International GEWEX Project Office, Silver Spring, MD, 11-12. [Available online at http:// www.gewex.org/gewex-content/files_mf/1432152398Aug2004. pdf.]

_ 2011: The terrestrial segment of soil moisture-climate coupling. Geophys. Res. Lett., 38, L16702, doi:10.1029/2011GL048268.

- 2013: Characteristics of the water cycle and land-atmosphere interactions from a comprehensive reforecast and reanalysis data set: CFSv2. Climate Dyn., 41, 1083-1097, doi:10.1007/ s00382-013-1866-x.

—, X. Gao, M. Zhao, Z. Guo, T. Oki, and N. Hanasaki, 2006: The Second Global Soil Wetness Project (GSWP-2): Multimodel analysis and implications for our perception of the land surface. Bull. Amer. Meteor. Soc., 87, 1381-1397, doi:10.1175/ BAMS-87-10-1381.

— C. A. Schlosser, and K. L. Brubaker, 2009: Precipitation, recycling, and land memory: An integrated analysis. J. Hydrometeor., 10, 278-288, doi:10.1175/2008JHM1016.1.

_, Y. Jin, B. Singh, and X. Yan, 2013a: Trends in land-atmosphere interactions from CMIP5 simulations. J. Hydrometeor., 14, 829849, doi:10.1175/JHM-D-12-0107.1.

, S. Kumar, M. J. Fennessy, E. L. Altshuler, T. DelSole, Z. Guo, B. Cash, and D. Straus, 2013b: Model estimates of 
land-driven predictability in a changing climate from CCSM4. J. Climate, 26, 8495-8512, doi:10.1175/JCLI-D-13-00029.1.

Dorigo, W. A., and Coauthors, 2011: The International Soil Moisture Network: A data hosting facility for global in situ soil moisture measurements. Hydrol. Earth Syst. Sci., 15, 16751698, doi:10.5194/hess-15-1675-2011.

Douville, H., 2003: Assessing the influence of soil moisture on seasonal climate variability with AGCMs. J. Hydrometeor., 4, 1044-1066, doi:10.1175/1525-7541(2003)004<1044:ATIOSM>2.0.CO;2.

Drusch, M., K. Scipal, P. de Rosnay, G. Balsamo, E. Andersson, P. Bougeault, and P. Viterbo, 2009: Towards a Kalman filter based soil moisture analysis system for the operational ECMWF Integrated Forecast System. Geophys. Res. Lett., 36, 110401, doi:10.1029/2009GL037716.

Ek, M. B., and A. A. M. Holtslag, 2004: Influence of soil moisture on boundary layer cloud development. J. Hydrometeor., 5, 8699, doi:10.1175/1525-7541(2004)005<0086:IOSMOB >2.0.CO;2.

— K. E. Mitchell, Y. Lin, E. Rogers, P. Grunmann, V. Koren, G. Gayno, and J. D. Tarpley, 2003: Implementation of Noah land surface model advances in the National Centers for Environmental Prediction operational mesoscale Eta model. J. Geophys. Res., 108, 8851, doi:10.1029/2002JD003296.

Entekhabi, D., and Coauthors, 2010: The Soil Moisture Active and Passive (SMAP) Mission. Proc. IEEE, 98, 704-716, doi:10.1109/ JPROC.2010.2043918.

Findell, K. L., and E. A. B. Eltahir, 2003: Atmospheric controls on soil moisture-boundary layer interactions: Part I: Framework development. J. Hydrometeor., 4, 552-569, doi:10.1175/ 1525-7541(2003)004<0552:ACOSML>2.0.CO;2.

—, P. Gentine, B. R. Lintner, and C. Kerr, 2011: Probability of afternoon precipitation in eastern United States and Mexico enhanced by high evaporation. Nat. Geosci., 4, 434-439, doi:10.1038/ngeo1174.

Gentine, P., A. A. M. Holtslag, F. D'Andrea, and M. Ek, 2013: Surface and atmospheric controls on the onset of moist convection over land. J. Hydrometeor., 14, 1443-1461, doi:10.1175/ JHM-D-12-0137.1.

Griffies, S. M., M. J. Harrison, R. C. Pacanowski, and A. Rosati, 2004: A technical guide to MOM4. GFDL Ocean Group Tech. Rep. 5, 281 pp. [Available online at http://data1.gfdl.noaa.gov/ arl/ pubrel $/ \mathrm{j} / \mathrm{mom} 4 \mathrm{beta} / \mathrm{src} / \mathrm{mom} 4 /$ doc/guide.pdf.]

Grumbine, R. W., 1996: Automated passive microwave sea ice concentration analysis at NCEP. NCEP OMB Tech. Note 120, $13 \mathrm{pp}$. [Available online at http://polar.ncep.noaa.gov/mmab/ papers/tn120/ssmi120.pdf.]

Guo, Z., and P. A. Dirmeyer, 2013: Interannual variability of landatmosphere coupling strength. J. Hydrometeor., 14, 16361646, doi:10.1175/JHM-D-12-0171.1.

— , and Coauthors, 2006: GLACE: The Global Land-Atmosphere Coupling Experiment. Part II: Analysis. J. Hydrometeor., 7, 611625, doi:10.1175/JHM511.1.

— P. A. Dirmeyer, T. DelSole, and R. D. Koster, 2012: Rebound in atmospheric predictability and the role of the land surface. J. Climate, 25, 4744-4749, doi:10.1175/JCLI-D-11-00651.1.

Han, J., and H.-L. Pan, 2011: Revision of convection and vertical diffusion schemes in the NCEP Global Forecast System. Wea. Forecasting, 26, 520-533, doi:10.1175/WAF-D-10-05038.1.

Hong, S.-Y., and H.-L. Pan, 1996: Nonlocal boundary layer vertical diffusion in a medium-range forecast model. Mon. Wea. Rev., 124, 2322-2339, doi:10.1175/1520-0493(1996)124<2322: NBLVDI $>2.0 . \mathrm{CO} ; 2$.

Kerr, Y., P. Waldteufel, J. P. Wigneron, J. M. Martinuzzi, J. Font, and M. Berger, 2001: Soil moisture retrieval from space: The
Soil Moisture and Ocean Salinity (SMOS) mission. IEEE Trans. Geosci. Remote Sens., 39, 1729-1735, doi:10.1109/ 36.942551.

Kobayashi, S., and Coauthors, 2015: The JRA-55 Reanalysis: General specifications and basic characteristics. J. Meteor. Soc. Japan, 93, 5-48, doi:10.2151/jmsj.2015-001.

Koster, R. D., M. J. Suarez, and M. Heiser, 2000: Variance and predictability of precipitation at seasonal-to-interannual timescales. J. Hydrometeor., 1, 26-46, doi:10.1175/1525-7541(2000)001<0026: VAPOPA $>2.0 . \mathrm{CO} ; 2$

—, P. A. Dirmeyer, A. N. Hahmann, R. Ijpelaar, L. Tyahla, P. Cox, and M. J. Suarez, 2002: Comparing the degree of landatmosphere interaction in four atmospheric general circulation models. J. Hydrometeor., 3, 363-375, doi:10.1175/ 1525-7541(2002)003<0363:CTDOLA > 2.0.CO;2.

— moisture and precipitation. Science, 305, 1138-1140, doi:10.1126/ science. 1100217.

_ Z Z. Guo, P. A. Dirmeyer, R. Yang, K. Mitchell, and M. J. Puma, 2009: On the nature of soil moisture in land surface models. J. Climate, 22, 4322-4335, doi:10.1175/2009JCLI2832.1.

_ , and Coauthors, 2010: Contribution of land surface initialization to subseasonal forecast skill: First results from a multimodel experiment. Geophys. Res. Lett., 37, L02402, doi:10.1029/ 2009GL041677.

—_ and Coauthors, 2011: The second phase of the Global LandAtmosphere Coupling Experiment: Soil moisture contributions to subseasonal forecast skill. J. Hydrometeor., 12, 805-822, doi:10.1175/2011JHM1365.1.

Lien, G.-Y., E. Kalnay, T. Miyoshi, and G. J. Huffman, 2016: Statistical properties of global precipitation in the NCEP GFS model and TMPA observations for data assimilation. Mon. Wea. Rev., 144, 663-679, doi:10.1175/MWR-D-15-0150.1.

Meehl, G. A., and W. M. Washington, 1988: A comparison of soilmoisture sensitivity in two global climate models. J. Atmos. Sci., 45, 1476-1492, doi:10.1175/1520-0469(1988)045<1476: ACOSMS $>2.0 . \mathrm{CO} ; 2$.

Merryfield, W. J., W.-S. Lee, G. J. Boer, V. V. Kharin, J. F. Scinocca, G. M. Flato, R. S. Ajayamohan, and J. C. Frye, 2013: The Canadian Seasonal to Interannual Prediction System. Part I: Models and initialization. Mon. Wea. Rev., 141, 2910 2945, doi:10.1175/MWR-D-12-00216.1.

Notaro, M., 2008: Statistical identification of global hot spots in soil moisture feedbacks among IPCC AR4 models. J. Geophys. Res., 113, D09101, doi:10.1029/2007JD009199.

Quiring, S. M., T. W. Ford, J. K. Wang, A. Khong, E. Harris, T. Lindgren, D. W. Goldberg, and Z. Li, 2015: North American Soil Moisture Database: Development and applications. Bull. Amer. Meteor. Soc., 97, 1441-1459, doi:10.1175/ BAMS-D-13-00263.1.

Reichle, R. H., W. T. Crow, and C. L. Keppenne, 2008: An adaptive ensemble Kalman filter for soil moisture data assimilation. Water Resour. Res., 44, W03423, doi:10.1029/2007WR006357.

Reynolds, R. W., T. M. Smith, C. Liu, D. B. Chelton, K. S. Casey, and M. G. Schlax, 2007: Daily high-resolution blended analyses for sea surface temperature. J. Climate, 20, 5473-5496, doi:10.1175/2007JCLI1824.1.

Rodell, M., and Coauthors, 2004: The Global Land Data Assimilation System. Bull. Amer. Meteor. Soc., 85, 381-394, doi:10.1175/ BAMS-85-3-381.

Roundy, J. K., C. R. Ferguson, and E. Wood, 2014: Impact of landatmospheric coupling in CFSv2 on drought prediction. Climate Dyn., 43, 421-434, doi:10.1007/s00382-013-1982-7. 
Saha, S., and Coauthors, 2010: The NCEP Climate Forecast System Reanalysis. Bull. Amer. Meteor. Soc., 91, 1015-1057, doi:10.1175/ 2010BAMS3001.1.

— , and Coauthors, 2014: The NCEP Climate Forecast System version 2. J. Climate, 27, doi:10.1175/JCLI-D-12-00823.1.

Santanello, J. A., C. D. Peters-Lidard, S. V. Kumar, C. Alonge, and W.-K. Tao, 2009: A modeling and observational framework for diagnosing local land-atmosphere coupling on diurnal time scales. J. Hydrometeor., 10, 577-599, doi:10.1175/2009JHM1066.1.

- - - and — 2011: Diagnosing the sensitivity of local landatmosphere coupling via the soil moisture-boundary layer interaction. J. Hydrometeor., 12, 766-786, doi:10.1175/ JHM-D-10-05014.1.

— S. V. Kumar, C. D. Peters-Lidard, and P. M. Lawson, 2016: Impact of soil moisture assimilation on land surface model spinup and coupled land-atmosphere prediction. J. Hydrometeor., 17, 517-540, doi:10.1175/JHM-D-15-0072.1.

Schlosser, C. A., and P. C. D. Milly, 2002: A model-based investigation of soil moisture predictability and associated climate predictability. J. Hydrometeor., 3, 483-501, doi:10.1175/ 1525-7541(2002)003<0483:AMBIOS > 2.0.CO;2.

Shin, C.-S., and B. Huang, 2016: Slow and fast annual cycles of the Asian summer monsoon in the NCEP CFSv2. Climate Dyn., 47, 529-553, doi:10.1007/s00382-015-2854.

Shukla, J., and Y. Mintz, 1982: Influence of land-surface evapotranspiration on the earth's climate. Science, 215, 1498-1501, doi:10.1126/science.215.4539.1498.

Tawfik, A. B., and P. A. Dirmeyer, 2014: A process-based framework for quantifying the atmospheric preconditioning of surface triggered convection. Geophys. Res. Lett., 41, 173-178, doi:10.1002/2013GL057984.

Taylor, C. M., A. Gounou, F. Guichard, P. P. Harris, R. J. Ellis, F. Couvreux, and M. De Kauwe, 2011: Frequency of Sahelian storm initiation enhanced over mesoscale soil-moisture patterns. Nat. Geosci., 4, 430-433, doi:10.1038/ngeo1173. van den Hurk, B., J. Ettema, and P. Viterbo, 2008: Analysis of soil moisture changes in Europe during a single growing season in a new ECMWF soil moisture assimilation system. J. Hydrometeor., 9, 116-131, doi:10.1175/2007JHM848.1.

Vitart, F., and A. W. Robertson, 2015: Sub-seasonal to seasonal prediction: Linking weather and climate. Seamless Prediction of the Earth System: From Minutes to Months, G. Brunet, S. Jones, and P. M. Ruti, Eds., WMO-No. 1156, 385-401.

- and Coauthors, 2016: The Subseasonal to Seasonal Prediction (S2S) project database. Bull. Amer. Meteor. Soc., doi:10.1175/ BAMS-D-16-0017.1, in press.

Waliser, D. E., 2005: Predictability and forecasting. Intraseasonal Variability of the Atmosphere-Ocean Climate System, W. K. M. Lau and D. E. Waliser, Eds., Springer, 433-476.

Wei, J., and P. A. Dirmeyer, 2012: Dissecting soil moistureprecipitation coupling. Geophys. Res. Lett., 39, L19711, doi:10.1029/2012GL052351.

World Meteorological Organization, 2011: Targeted observations for improving numerical weather prediction: An overview. WWRP/THORPEX Rep. 15, 37 pp.

Xie, P., and P. A. Arkin, 1997: Global precipitation: A 17-year monthly analysis based on gauge observations, satellite estimates, and numerical model outputs. Bull. Amer. Meteor. Soc., 78, 2539-2558, doi:10.1175/1520-0477(1997)078<2539: GPAYMA $>2.0 . \mathrm{CO} ; 2$.

—, M. Chen, A. Yatagai, T. Hayasaka, Y. Fukushima, and S. Yang, 2007: A gauge-based analysis of daily precipitation over East Asia. J. Hydrometeor., 8, 607-626, doi:10.1175/JHM583.1.

Zeng, X., M. Barlange, C. Castro, and K. Fling, 2010: Comparison of land-precipitation coupling strength using observations and models. J. Hydrometeor., 11, 979-994, doi:10.1175/ 2010JHM1226.1.

Zhang, L., P. A. Dirmeyer, J. Wei, Z. Guo, and C.-H. Lu, 2011: Land-atmosphere coupling strength in the Global Forecast System. J. Hydrometeor., 12, 147-156, doi:10.1175/2010JHM1319.1. 